\title{
Recht und Verfahren des Bundesrates: unverzichtbarer Wegweiser
}

Reuter, Konrad: Praxishandbuch Bundesrat. Verfassungsrechtliche Grundlagen, Kommentar zur Geschäftsordnung, Praxis des Bundesrates, 2. neu bearbeitete Auflage, C. F. Müller, Heidelberg 2007, 749 Seiten, € 108,-.

Wenn Bundestag und Bundesrat von unterschiedlichen politischen Lagern dominiert werden, rückt der Bundesrat in den Mittelpunkt des politischen Geschehens. Die Opposition im Bundestag versucht, Bundestagsentscheidungen im Bundesrat zu ändern, zu korrigieren und - je näher die Bundestagswahl rückt - um so mehr auch zu blockieren. Bundesregierung und die sie tragende Mehrheit versuchen, ihre politischen Vorhaben möglichst unbeschädigt im Bundesrat „durchzubringen“. Dies ist eine politische Konstellation voller Konflikte, die gelegentlich auch mit Hilfe des Rechts und der Geschäftsordnung ausgetragen werden. Hier ist Konrad Reuters Handbuch ein unentbehrlicher Ratgeber geworden. Einem breiteren Publikum bekannt wurde der „Reuter“, als er im Streit um das Zuwanderungsgesetz mehrfach zitiert wurde - damals hing die Zustimmung des Bundesrats davon ab, ob Brandenburgs Ja-Stimme gültig war. ${ }^{1}$

Dass das Praxishandbuch gerade jetzt neu aufgelegt wird, hat einen guten Grund: Die Föderalismusreform 2006 hat die Rechtsstellung des Bundesrats verändert. Gleichzeitig hat Reuter das Handbuch in Bezug auf Rechtsprechung, Schrifttum und Staatspraxis auf den aktuellen Stand gebracht.

Die Neuauflage verzichtet auf den Abdruck der einschlägigen Normen, sie können im Internet unter www.bundesrat.de in der aktuellen Fassung abgerufen werden. Dafür ist der Umfang der Kommentierung um etwa 90 Seiten angewachsen. So setzt sich Reuter ausführlich damit auseinander, dass die Bundesregierung immer wieder Gesetzesvorhaben durch die Regierungsfraktionen einbringen lässt und damit den ersten Bundesratsdurchgang nach Art. 76 Abs. 2 GG umgeht. Reuter wendet gegen diese Praxis ein, dass sich der scheinbare Zeitgewinn bis zum Beginn der Bundestagsberatung oft genug in sein Gegenteil verkehre, wenn die Umgehung des Bundesrats ein langwieriges Vermittlungsverfahren provoziere. Der erste Durchgang diene auch der „guten Gesetzgebung“, denn die Länder könnten ihre Sachkompetenz und Verwaltungserfahrung frühzeitig in die Gesetzesberatung einbringen. Wer im Bund oder den Ländern mit Gesetzgebung praktisch befasst ist, weiß, wie gewichtig dieses Argument ist. Der Streit wird allerdings weiter schwelen, bis das Bundesverfassungsgericht Gelegenheit hat, ihn zu entscheiden. Solange die Große Koalition Bundestag und Bundesrat beherrscht, wird es darüber jedoch vermutlich nicht zu einem akuten Verfahren kommen.

Die Rezension der Vorauflage ${ }^{2}$ kritisierte Reuters Wertung des parteipolitischen Einflusses im Bundesrat. Dass es ihn gibt, und dass er in einer Demokratie nicht nur unvermeidbar ist, sondern auch legitim, ist die eine Seite. Dass er die politische Verantwortlichkeit zwischen Bund und Ländern verwischt und zu politischen Blockaden führen kann, ist die andere Seite, mit der sich Reuter in der Neuauflage nunmehr vertieft auseinandersetzt (Art. 50 GG, Rn. 66 ff.). Er plädiert weiterhin für einen starken Bundesrat als föderatives Gegengewicht auf Bundesebene. Die Erfahrungen beider politischer Lager mit einer vom

1 BVerfGE 106, S. 310.

2 Uwe Leonardy, Der Bundesrat in Recht und Staatspraxis, in: ZParl, 23. Jg. (1992), H. 2, S. 381 ff. 
Gegner dominierten Länderkammer haben allerdings dazu beigetragen, in der Föderalismusreform einen anderen Weg zu gehen: die Stärkung der eigenständigen Gesetzgebungszuständigkeiten von Bund und Ländern. Ob diese - partielle - Entflechtung der Gesetzgebungszuständigkeiten in der politischen Praxis spürbar wird und ob sie die Rolle des Bundesrats schwächt, bleibt allerdings abzuwarten.

Unverändert verteidigt Reuter das „freie Mandat“ der Landesregierungen gegenüber der Einflussnahme der Landesparlamente. Diese können den Regierungen keine verbindlichen Weisungen für die Stimmabgabe im Bundesrat geben; das ist unumstritten. Entgegen der Ansicht von Reuter dürften unverbindliche - oder besser gesagt, „nur“ politisch verbindliche - „Empfehlungen“ oder „Orientierungshilfen“ dagegen unproblematisch sein, denn die parlamentarische Kontrolle einer Landesregierung erstreckt sich selbstverständlich auch auf deren Verhalten im Bundesrat. Deshalb kann das Landesparlament genauso wie zum Beispiel zum Gesetzesvollzug, zu politischen Programmen oder zu administrativen Einzelfällen Wünsche, Anregungen und Forderungen an die Landesregierung richten. Und genauso selbstverständlich entscheidet die Regierung nach eigenem politischen Ermessen - und auf eigenes politisches Risiko -, inwieweit sie ihnen folgt. Zu praktischen Problemen führt das in der Regel nicht: Zum einen stimmt sich die Landesregierung mit der sie tragenden Mehrheit im Parlament ohnehin über ihr Verhalten im Bundesrat ab, wenn es um politisch bedeutsame Fragen geht. Zum anderen fehlt den Landtagen die Arbeitskapazität, um die Bundesratspolitik umfassend zu kontrollieren und zu begleiten.

Die aufgeführten Punkte zeigen, dass Reuter pointiert Positionen bezieht zugunsten des Bundesrats. Sie regen an zur Diskussion, und das ist für ein wissenschaftliches Werk ein Kompliment. Im Übrigen bleibt Reuter der zuverlässige und gründliche Kommentator nicht nur der einschlägigen verfassungsrechtlichen Grundlagen, sondern auch der Geschäftsordnung des Bundesrats.

$\mathrm{Zu}$ begrüßen ist das ausführliche Sachverzeichnis, es erleichtert das Nachschlagen beträchtlich. Was den Rezensenten allerdings stört, nicht nur in Reuters Handbuch, ist die Unsitte, mit Fettdruck einzelne Wörter oder Passagen hervorzuheben. Der gut aufgebaute und gegliederte Text gibt dem Leser ausreichend Orientierung.

Im Geleitwort hat der damalige Bundesratspräsident Peter Harry Carstensen das Handbuch als „unverzichtbaren Wegweiser“ mit hohem Nutzen für die Praxis und Wissenschaft bezeichnet. Dem kann sich der Rezensent nur anschließen.

Florian Edinger

\section{Politische Strategie: Grundlegung für Forschung und Praxis}

Raschke, Joachim und Ralf Tils: Politische Strategie. Eine Grundlegung, VS Verlag für Sozialwissenschaften, Wiesbaden 2007, 585 Seiten, $€ 39,90$.

„Wenn man erst einmal als Machtmensch angesehen wird, der alles kühl plant, gerinnt der Zufall zur Strategie. Doch häufig ist es weit weniger Strategie, als man es vermutet", so wurde Gerhard Schröder in der 1996 publizierten Biographie zitiert ${ }^{1}$. Möglichkeiten und

1 Béla Anda / Rolf Kleine, Gerhard Schröder. Eine Biographie, Berlin 1996, S. 246. 